\title{
Possible Contamination from Rainwater in Community Pool
}

David McGregor

University of South Florida

Advisors:

Arcadii Grinshpan, Mathematics and Statistics

Robert Powell, Environ

Problem Suggested By: Robert Powell

Follow this and additional works at: https://digitalcommons.usf.edu/ujmm

Part of the Mathematics Commons

UJMM is an open access journal, free to authors and readers, and relies on your support:

Donate Now

\section{Recommended Citation}

McGregor, David (2021) "Possible Contamination from Rainwater in Community Pool," Undergraduate Journal of Mathematical Modeling: One + Two: Vol. 12: Iss. 1, Article 3.

DOI: https://doi.org/10.5038/2326-3652.12.1.4935

Available at: https://digitalcommons.usf.edu/ujmm/vol12/iss1/3 


\title{
Possible Contamination from Rainwater in Community Pool
}

\begin{abstract}
The project is meant to create an equation that can be used to estimate the amount of organic pollutant bacteria - that is present in a swimming pool per day from rainwater. This equation is derived through a differential equation of the rate in minus the rate out. The created differential equation is an ordinary linear differential equation and is solved using an integration factor. The general solution is then converted into a specific equation using an initial condition. The resulting equation provides an approximate number of organic contaminants $x(t)$ present in the pool after an amount of time in days $(t)$. The equation finds that the pool - during its closure - has been cleaned often enough. It also provides a method to estimate the amount of contamination from rain after any other extended closures.
\end{abstract}

\section{Keywords}

Community pool, Covid-19, organic pollutant (bacteria), linear differential equation

Creative Commons License

(c) (i) (2)

This work is licensed under a Creative Commons Attribution-Noncommercial-Share Alike 3.0 United States License. 


\section{PROBLEM STATEMENT}

Create an equation to measure the amount of organic contaminants that are present in a local pool after contamination from rain.

\section{MOTIVATION}

Now that people are beginning to be vaccinated and we are nearing the end of the Covid-19 pandemic, a greater number of people are beginning to go back to normal activities. Swimming is likely to become a frequent activity for many people as things start to open back up. The community pool in my neighborhood, for example, plans to reopen in the coming weeks to accommodate swimmers in my community, however, during its closure maintenance was reduced to save money and the pool was cleaned only once a month. The pool was cleaned less often because it was not being used but other factors could contaminate the pool such as rain. Contaminants from rainwater could lead to contamination if the pool is not cleaned often enough. So, an equation can be derived to find the approximate amount of organic contaminants at any given time after a cleaning.

\section{MATHEMATICAL DESCRIPTION AND SOLUTION APPROACH}

The first step to deriving an equation for the approximate amount of contaminants present in the pool would be to find the volume of the pool. A sketch of the pool is below:

Figure (1)

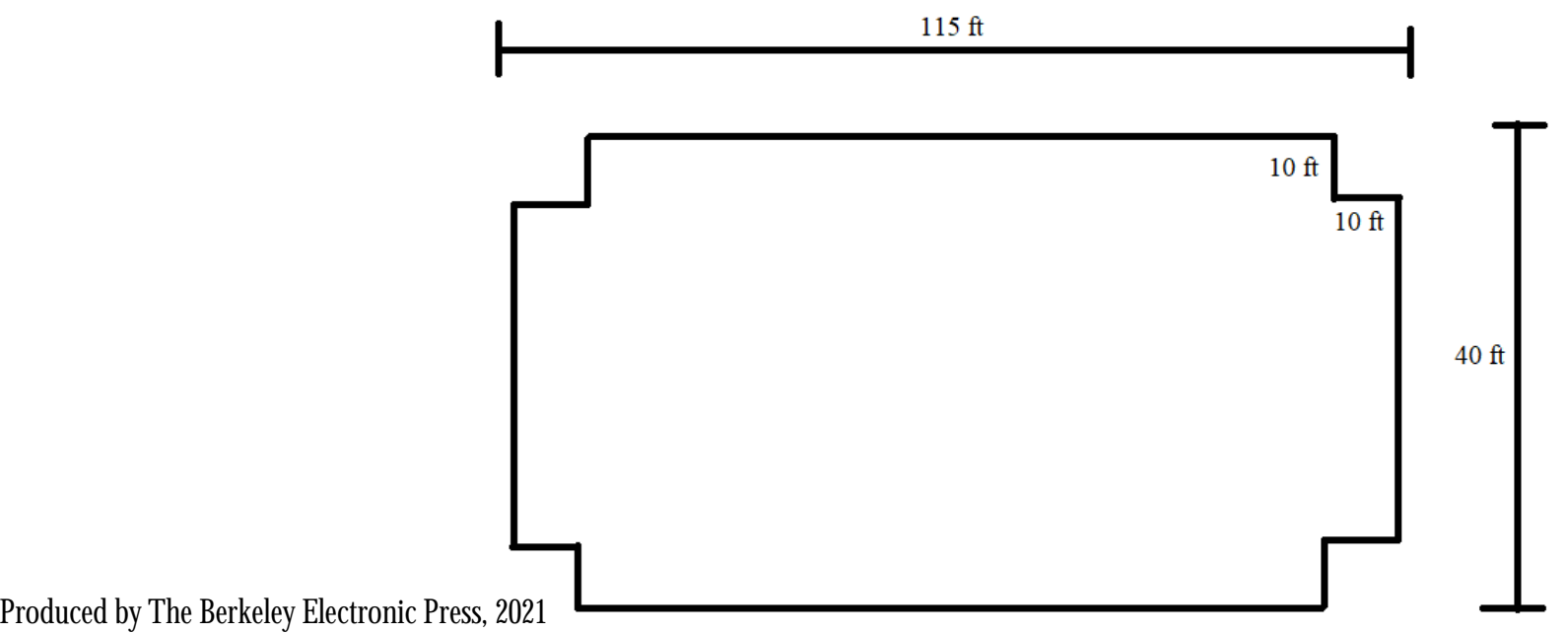


This problem is based on water flow into the pool and primarily is a function of TOTAL RATE $=$ RATE IN - RATE OUT .

The pool is a $115 \mathrm{ft}$ by $40 \mathrm{ft}$ rectangle with four $10 \mathrm{ft}$ by $10 \mathrm{ft}$ squares removed from the corners. This leaves us with an area of 4200 square feet. Then to find the volume we multiply by the average depth of the pool, which in this case is 4.6 feet. This gives an estimated volume of 19320 cubic feet to fill up the pool.

The next step is to find the amount of rainwater that will flow into the pool on any average day. On average Florida receives 54 inches of rain throughout the year (NOAA National Centers for Environmental Information), this equates to 4.5 inches per month and 0.15 inches per day. With an average of 0.15 inches per day, this means that it is expected for 52.5 cubic feet of rain to land in the pool each day $(0.15$ inches $\times 4200$ square feet $)$.

After calculating the amount of rainwater expected on an average day we should calculate the contaminants that will be present in this amount of rainwater. A study done on samples of rainwater collected in populated areas found unsafe amounts of both Fecal Coliform and Enterococci bacteria present in many of the samples taken, with a high of 172 organisms per $100 \mathrm{ml}$ (Science Direct). The calculated value of 52.5 cubic feet of rain can be converted to 1486634 milliliters. This value for milliliters can then be multiplied with the ratio of organisms per $100 \mathrm{ml}$ to give 2557011 organic contaminants per day from the expected rain.

The Next step is to determine the rate out of contaminants. It is known that the pool drains . 1 inches of water per day to account for the addition of rain, meaning drainage of 35 square feet per day. To find the rate out we must first calculate the rate of change for the volume which is equal to $19320+17.5 \times t$, where $t$ is equal to days. This means that 17.5 cubic feet are added per day. We then multiply the amount drained -35 cubic feet- by an unknown value of contaminants drained, denoted by $x$. This leaves us with $\frac{35 x}{19320+17.5 t}$ as the rate of flow out of the pool.

Now that we have calculated both rate in and rate out, we can set up a differential equation:

$$
\frac{d x}{d t}=2557011-\frac{35 x}{19320+17.5 t}
$$

This represents the total rate of the system as the rate in minus the rate out. Equation (1) is a first order linear differential equation. So, the next step is to rewrite (1) in the first order linear form (2): 


$$
x^{\prime}+\frac{35}{19320+17.5 t} x=2557011
$$

Now we will find an integrating factor to solve the differential equation (2):

$$
\mu(t)=e^{\int \frac{35 d t}{19320+17.5 t}}
$$

After creating the equation for $\mu(t)$ we simplify by computing the integral in (3) using a usubstitution:

$$
u=19320+17.5 t
$$

$35 \int \frac{d t}{19320+17.5 t}=\frac{35}{17.5} \int \frac{1}{u} d u=2 \ln (u)$

Next $19320+17.5 t$ is back in for $\mathrm{u}$ :

$$
2 \ln (19320+17.5 t)
$$

Now that the integral has been solved, we simplify $\mu(t)$ in (3):

$$
\mu(\mathrm{t})=e^{2 \ln (19320+17.5 t)},
$$

hence

$$
\mu(t)=(19320+17.5 t)^{2}
$$

When the integrated factor has been calculated we can multiply the original differential equation (2) by the integration factor (5):

$$
\begin{gathered}
x^{\prime} \times(19320+17.5 t)^{2}+\frac{35}{(19320+17.5 t)} \times(19320+17.5 t)^{2} \times x \\
=2557011 \times(19320+17.5 t)^{2}
\end{gathered}
$$


As the equation (2) has been multiplied by the integration factor its left side is equal to the derivative of the product of two functions:

$$
\left((19320+17.5 t)^{2} \times x\right)^{\prime}=2557011(19320+17.5 t)^{2}
$$

Next we take the integral of both sides:

$$
(19320+17.5 t)^{2} \times x=\int 2557011(19320+17.5 t)^{2} d t
$$

Then we solve the integral using u-substitution (4):

$$
\begin{gathered}
2557011 \int(19320+17.5 t)^{2} d t \\
=\frac{2557011}{17.5} \int u^{2} d u \\
=\frac{2557011}{17.5} \times \frac{u^{3}}{3}+c \\
=\frac{2557011}{52.5} \times(19320+17.5 t)^{3}+c
\end{gathered}
$$

Now that the integral has been solved we can isolate the variables of equation (2):

$$
(19320+17.5 t)^{2} \times x=\frac{2557011}{52.5} \times(19320+17.5 t)^{3}+c,
$$

hence

$$
x=\frac{2557011(19320+17.5 t)}{52.5}+\frac{c}{(19320+17.5 t)^{2}}
$$


This represents the general solution but in the case of the pool we have an initial condition and can solve for a specific condition. Prior to reopening the pool will be cleaned and presumably should have no contaminants. Therefore, the initial condition will be $x(0)=0$ as there are no contaminants in the pool and no time will have passed. Using this we can solve for the value of $c$.

$$
\begin{gathered}
0=\frac{2557011(19320+17.5(0)}{52.5}+\frac{c}{(19320+17.5(0))^{2}} \\
c=\frac{-2557011(19320)^{3}}{52.5}
\end{gathered}
$$

This can then be plugged back into the equation (6) to give the specific solution:

$$
x=\frac{2557011(19320+17.5 t)}{52.5}+\frac{\frac{-2557011(19320)^{3}}{52.5}}{(19320+17.5 t)^{2}}
$$

It follows that

$$
x(t) \approx 48705\left[19320+17.5 t-(19320)^{3}(19320+17.5 t)^{-2}\right]
$$

Equation (7) represents an approximate number of organic contaminants $x(t)$ that can be found in the entire volume of the pool relative to the number of days $(t)$ since the pool has been cleaned. 


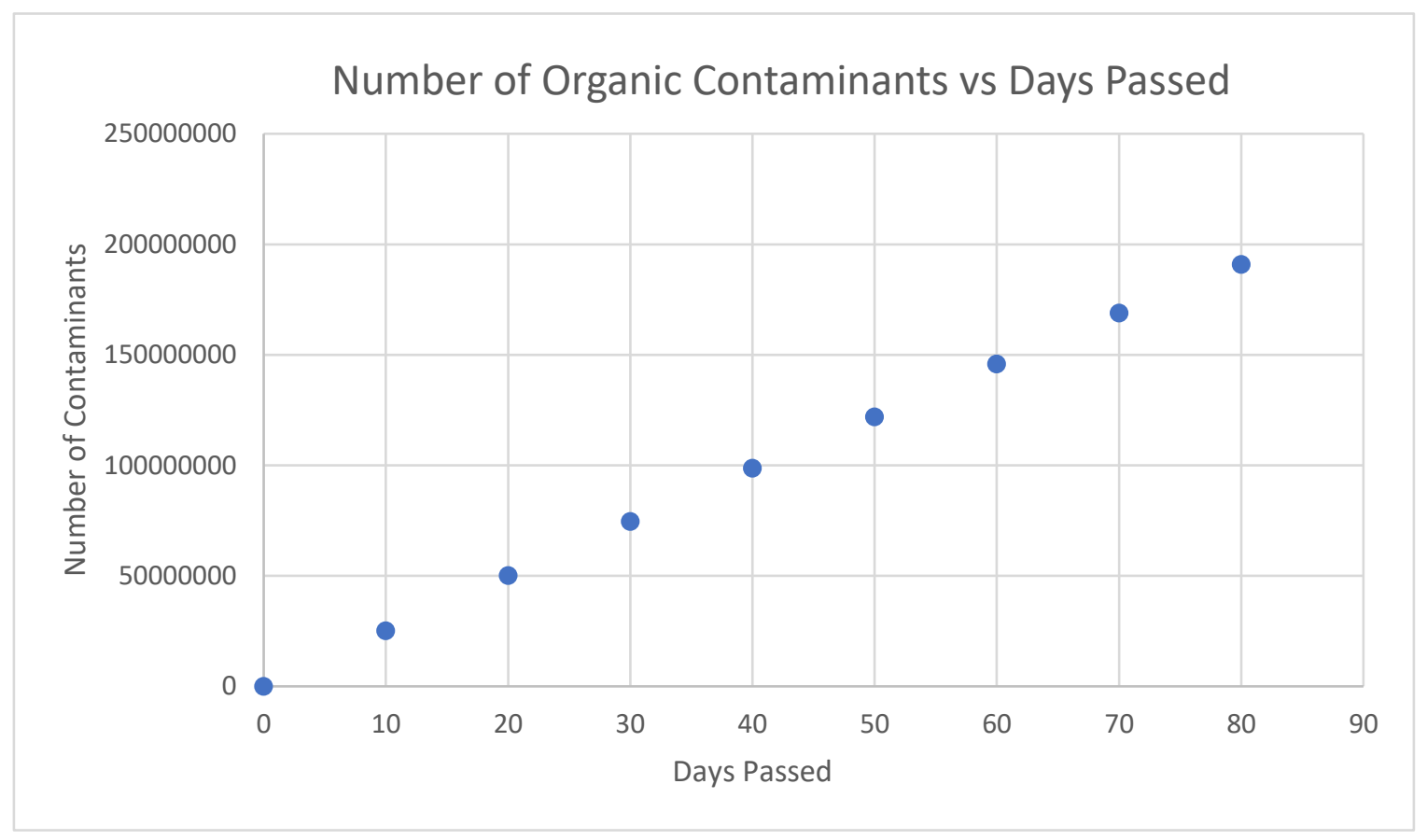

Figure (2)

\section{DISCUSSION}

This project gives an equation that can be used to model an approximate number of organic contaminants from rain that can be found in the community pool on any given day. Equation (7) is an overestimate, being based on the absolute highest measurements of organic contaminants. This is to ensure that the estimate is not underrepresenting the number of contaminants present in the pool and that the level of contamination is never over safe limits. The safe limit for these organic organisms is 33 organisms per 100 milliliters of water according to the EPA. The volume of the pool is approximately 19320 cubic feet which is equivalent to 5470810000 milliliters. This means that the pool can have at most $1.853673 \mathrm{E}-8$ of these bacteria and still be at a safe level. This number is exceeded on the $75^{\text {th }}$ day of not cleaning the pool with the only contamination coming from rainwater- shown in Figure (2). 


\section{CONCLUSION AND RECOMMENDATIONS}

Equation (7) can be used to predict the amount of organic contaminants that is present in the pool at any given time. This can be used to ensure that the pool has been cleaned often enough for the levels of these organic contaminants to be safe for public use. This allows the owners of the pool to keep the pool safe for public use while also not requiring the pool to be cleaned more than necessary during the closure. The pool has been cleaned every 30 days during its closure which is more than often enough to ensure that the organic contaminants present in the pool are at a safe level. This equation can also be useful if the community pool is forced to close again for an extended period. It will allow the owners to cost effectively clean the pool in another long-term closure.

\section{NOMENCLATURE}

$\mathrm{ft}=$ feet $\quad$ (square feet, cubic feet); in=inch $\quad(\mathrm{in}=0.0833333$ foot $)$

$\mathrm{ml}=$ milliliter $\quad($ cubic foot $=28316.85 \mathrm{ml})$

$x$ - an approximate number of organic contaminants present in the pool after an amount of time

$t$ - time in days

\section{REFERENCES:}

1. NOAA National Centersfor Environmental InformationState Climate Summaries. Florida State Summaries 2019. (n.d.).

https://statesummaries.ncics.org/chapter/fl/\#: :text=During\%20July\%2C\%20typi cally\%20the\%20hottest,months\%20of\%20June\%20through\%20September.

2. Brownell, M. J., Harwood, V. J., Kurz, R. C., McQuaig, S. M., Lukasik, J., Scott, T. M.; Confirmation of putative stormwater impact on water quality at a Florida beach by microbial source tracking methods and structure of indicator organism populations.

Water Research, Volume 41, Issue 16, August 2007, Pages 3747-3757. https://www.sciencedirect.com/science/article/pii/S0043135407002485\#tblfn1a. 